\title{
Location-Price Competition in Airline Networks
}

\author{
H. Gao, ${ }^{1}$ J. Hu, ${ }^{2}$ V. Mazalov, ${ }^{3}$ A. Shchiptsova, ${ }^{3}$ L. Song, ${ }^{1}$ and J. Tokareva ${ }^{4}$ \\ ${ }^{1}$ College of Mathematics, Qingdao University, 308 Ningxia Road, Qingdao 266071, China \\ ${ }^{2}$ Business School, Qingdao University, 308 Ningxia Road, Qingdao 266071, China \\ ${ }^{3}$ Institute of Applied Mathematical Research, Karelian Research Centre of the Russian Academy of Sciences, \\ Pushkinskaya Street 11, Petrozavodsk 185910, Russia \\ ${ }^{4}$ Transbaikal State University, Alexandro-Zavodskaya Street 30, Chita 672039, Russia \\ Correspondence should be addressed to V. Mazalov; vlmazalov@yandex.ru
}

Received 28 February 2014; Accepted 25 June 2014; Published 14 July 2014

Academic Editor: X. Zhang

Copyright (C) 2014 H. Gao et al. This is an open access article distributed under the Creative Commons Attribution License, which permits unrestricted use, distribution, and reproduction in any medium, provided the original work is properly cited.

\begin{abstract}
This paper addresses location-then-price competition in airline market as a two-stage game of $n$ players on the graph. Passenger's demand distribution is described by multinomial logit model. Equilibrium in price game is computed through best response dynamics. We solve location game using backward induction, knowing that airlines will choose prices from equilibrium for the second-stage game. Some numerical results for airline market under consideration are presented.
\end{abstract}

\section{Introduction}

The aim of this paper is to characterize airline behavior in the market in both strategic and operational levels. In a competitive environment an airline makes a strategic decision on how to allocate planes among available routes. Starting operations on chosen routes airlines compete for passengers using ticket prices.

Location-then-price competition was first introduced by Hotelling [1]. This classical model examines behavior for two firms producing homogenous goods on a line segment. Passenger demand depends on the firm's price and transportation costs. Hotelling found price equilibrium and raised a problem of firms' competitive location. The nonexistence of location equilibrium in Hotelling model was shown in [2]. Extensions to Hotelling's duopoly were studied in several directions. Different forms of transportation costs were used in $[2,3]$. In [4-6], Hotelling's model is examined on more complex set than line segment. Location-then-price competition on the plane was studied in [6-8], where different forms of transportation costs are used. These models can be applied in transportation networks (with Euclidian distance) and in mobile and telecommunication networks (with Manhattan distance). Price competition among more than two firms is addressed in [9], where sufficient conditions on the existence of Nash equilibrium in price game for any number of firms are introduced.

In this paper we examine location-then-price Hotelling model on the graph for the case of $n \geq 2$ players. Results of theoretical analysis for proposed model are applied to study competition in airline market, where airlines first decide plane allocation and then choose ticket prices.

This paper is organized as follows. In Section 2 we describe model notations and assumptions. In Section 3 the main results about the equilibrium existence in price and location games with logit analysis application are given. Airline market data is described in Section 4. In this section analysis of price and location equilibrium is performed and results are applied to find location-then-price equilibrium in airline markets under consideration. Some remarks are given in the final section.

\section{Location Game-Theoretic Model on Graph}

Consider a market where the customers are distributed in the vertexes of the transportation graph $G(V, E)$. The edges of the graph are transportation links (railways, car, air lines, etc.). The vertexes are the hubs (bus stops, airports, railway stations, etc.). The customers are the passengers, who use this 
kind of transportation. The demand is determined by the flow of passengers. Notice that graph $G$ can be unconnected.

There are $n$ companies (players), who make a service in this market. A service is possible only if there is a link $e_{j} \in E$ between two vertexes in graph $G(V, E)$. The demand is determined by the number of customers in vertexes $v_{1}, v_{2} \in V$ connected by the link $e_{j}$ :

$$
d\left(e_{j}\right)=d\left(v_{1}, v_{2}\right), \quad e_{j}=\left(v_{1}, v_{2}\right) .
$$

Assume that player $i$ has $m_{i}$ units of a resource. He distributes the resource among links in graph $G(V, E)$. Suppose that each player $i$ distributes all $m_{i}$ units of resource and forms transportation network $E^{i}$, which is a subset of the links in graph $G(V, E)$.

A competition exists on the link $e_{j}$ only if it is included into several transportation networks:

$$
\exists i, j: E^{i} \cap E^{j} \neq \emptyset, \quad i, j \in N, \quad i \neq j .
$$

The demand on the link $e_{j}$ is distributed between players. Each of them makes a service of the part $M_{i j}$ of the customers on this link. Players announce prices for the service on the link $e_{j}$. The part of customers, which prefer the service of player $i$, depends on the price $p_{i j}$ and the prices of other players on this link:

$$
M_{i j}=M_{i j}\left(p_{i j},\left\{p_{r j}\right\}_{r \in N_{j} \backslash\{i\}}\right), \quad\left|M_{i j}\right| \leq 1,
$$

where $N_{j}$ is the number of the rival players on the link $e_{j}$.

The number of customers who prefer the service $i$ on the $\operatorname{link} e_{j}$ is

$$
S_{i j}\left(\left\{p_{r j}\right\}_{r \in N_{j}}\right)=M_{i j}\left(p_{i j},\left\{p_{r j}\right\}_{r \in N_{j} \backslash\{i\}}\right) d\left(e_{j}\right) .
$$

Let $x_{i j}$ be a distribution of player $i$ on the link $e_{j}$; that is,

$$
x_{i j}= \begin{cases}1, & e_{j} \in E^{i}, \\ 0, & \text { otherwise. }\end{cases}
$$

Player $i$ with $m_{i}$ units of the resource on graph $G(V, E)$ can attract customers, whose number equals

$$
S_{i}=\sum_{j=1}^{|E|} M_{i j}\left(p_{i j},\left\{p_{r j}\right\}_{r \in N_{j} \backslash\{i\}}\right) d\left(e_{j}\right) x_{i j} .
$$

The gain of player $i$ on the link $e_{j}$ depends on the price for the service and the share in the customer demand:

$$
h_{i j}\left(\left\{p_{r j}\right\}_{r \in N_{j}}\right)=p_{i j} M_{i j}\left(p_{i j},\left\{p_{r j}\right\}_{r \in N_{j} \backslash\{i\}}\right) d\left(e_{j}\right) \text {. }
$$

Denote by $c_{i j}$ the costs of player $i$ on the link $e_{j}$. The costs are proportional to the number of customers, who use the resource. Then the payoff of player $i$ on graph $G(V, E)$ is

$$
\begin{aligned}
H_{i}( & \left.\left\{p_{r}\right\}_{r \in N},\left\{x_{r}\right\}_{r \in N}\right) \\
= & \sum_{j=1}^{|E|}\left(h_{i j}\left(p_{i j},\left\{p_{r j}\right\}_{r \in N_{j} \backslash\{i\}}\right)\right. \\
& \left.-c_{i j} S_{i j}\left(p_{i j},\left\{p_{r j}\right\}_{r \in N_{j} \backslash\{i\}}\right)\right) x_{i j},
\end{aligned}
$$

where $p_{r}$ is a vector of prices of player $r$ in his network $E^{r}$ and $x_{r}$ is a vector, which defines allocation of $m_{r}$ units of the resource on graph $G(V, E)(r \in N)$.

First, players form their transportation networks and then they announce the prices for the service. The objective of a player is to maximize the payoff.

We determine the noncooperative game $\Gamma_{G}$ for $n$ players. Strategy of player $i$ is a pair of vectors $\left(x_{i}, p_{i}\right)$. Player determines the allocation $x_{i}$ of $m_{i}$ units of the resource:

$$
\forall j \in\{1, \ldots,|E|\}: x_{i j} \in\{0,1\}, \quad \sum_{r=1}^{|E|} x_{i r}=m_{i} .
$$

Then player $i$ announces the prices in his network $E^{i}$ :

$$
\forall j p_{i j} \in[0, \infty), \quad e^{j} \in E^{i} .
$$

The game has three stages.

(1) The players simultaneously distribute the resources given by $\left\{x_{i}\right\}_{i \in N}$.

(2) The players simultaneously announce the prices $\left\{p_{i}\right\}_{i \in N}$.

(3) Customers choose a service and the players receive the payoffs $\left\{H_{i}\right\}_{i \in N}$ depending on their transportation networks and prices.

We seek the Nash equilibrium $\left\{x_{i}^{*}\right\}_{i \in N}$, that is, $x_{i}^{*}$, such that $\forall x_{i}, i \in N$ it satisfies the condition

$$
\begin{aligned}
& H_{i}\left(\left\{\tilde{p}_{r}\left(x_{i},\left\{x_{r}^{*}\right\}_{r \in N \backslash\{i\}}\right)\right\}_{r \in N}, x_{i},\left\{x_{r}^{*}\right\}_{r \in N \backslash\{i\}}\right) \\
& \quad \leq H_{i}\left(\left\{\tilde{p}_{r}\left(x_{i}^{*},\left\{x_{r}^{*}\right\}_{r \in N \backslash\{i\}}\right)\right\}_{r \in N}, x_{i}^{*},\left\{x_{r}^{*}\right\}_{r \in N \backslash\{i\}}\right),
\end{aligned}
$$

where $\left\{\tilde{p}_{r}\left(\left\{x_{i}\right\}_{i \in N}\right)\right\}_{r \in N}$ is an equilibrium in price game for fixed resource distribution on graph $G(V, E)$.

For fixed resource allocation $\left\{\tilde{x}_{r}\right\}_{r \in N}$ we find the Nash equilibrium $\left\{p_{i}^{*}\right\}_{i \in N}$; that is, $p_{i}^{*}$, such that $\forall p_{i}, i \in N$ holds. Consider

$$
H_{i}\left(p_{i},\left\{p_{r}^{*}\right\}_{r \in N \backslash\{i\}},\left\{\tilde{x}_{r}\right\}_{r \in N}\right) \leq H_{i}\left(p_{i}^{*},\left\{p_{r}^{*}\right\}_{r \in N \backslash\{i\}},\left\{\tilde{x}_{r}\right\}_{r \in N}\right) .
$$

\section{Logit Analysis in Price Game on Graph}

Consider the number of players $N_{j}$, who choose the link $e_{j}$ in graph $G(V, E)$. Player $i \in N_{j}$ announces the price $p_{i j}$ for the service on the link $e_{j}$. Suppose that demand $d\left(e_{j}\right)$ is distributed among services in the logistic manner. Then

$$
M_{i j}=\frac{e^{\alpha p_{i j}+\left(a, v_{i}\right)}}{\sum_{s=1}^{\left|N_{j}\right|} e^{\alpha p_{s j}+\left(a, v_{s}\right)}+e^{\rho}}, \quad e_{j} \in E^{i}, i \in N_{j},
$$

where $v_{i}$ is a vector of characteristics of the service $i, \alpha<0$, $a$ is a constant vector of weights, and $\rho$ corresponds to the customers, who prefer not to use any service at all.

On the link $e_{j}$ we obtain price game of $N_{j}$ players with the payoffs:

$$
h_{i j}\left(\left\{p_{r j}\right\}_{r \in N_{j}}\right)=\left(p_{i j}-c_{i j}\right) M_{i j} d\left(e_{j}\right), \quad i \in N_{j} .
$$


Let us denote by $\left\{p_{i j}^{*}\right\}_{i \in N_{j}}$ an equilibrium in price game. It can be found as a solution of the system of equations

$$
\frac{\partial h_{i j}}{\partial p_{i j}}=M_{i j} d\left(e_{j}\right)\left(1+\alpha\left(p_{i j}-c_{i j}\right)\left(1-M_{i j}\right)\right)=0 .
$$

Imagine that a new player appears on the link $e_{j}$. What happens with equilibrium prices and payoffs? Denote by $\gamma$ a new player and consider the new set of players on the link $e_{j} \widetilde{N}_{j}=N_{j} \cup\{\gamma\}$. Let $\left\{\widetilde{p}_{i j}^{*}\right\}_{i \in \widetilde{N}_{j}}$ be an equilibrium in the price game with additional player.

Theorem 1. In the price game with additional player the equilibrium prices for all players except the new one are decreasing; that is, $\forall i \in N_{j}: p_{i j}^{*}>\tilde{p}_{i j}^{*}$.

Proof. Equilibrium prices in the game on the link $e_{j}$ with $N_{j}$ players satisfy the following equations:

$$
1+\alpha\left(p_{i j}-c_{i j}\right)\left(1-M_{i j}\right)=0, \quad i \in N_{j} .
$$

Rewrite it in the following form:

$$
\begin{aligned}
& \sum_{r \in N_{j}} e^{\alpha p_{r j}+\left(a, v_{r}\right)}+e^{\rho}+\alpha\left(p_{i j}-c_{i j}\right) \\
& \times\left(\sum_{r \in N_{j} \backslash\{i\}} e^{\alpha p_{r j}+\left(a, v_{r}\right)}+e^{\rho}\right)=0, \quad i \in N_{j} .
\end{aligned}
$$

It yields

$$
e^{\rho}+\sum_{r \in N_{j} \backslash\{i\}} e^{\alpha p_{r j}+\left(a, v_{r}\right)}=\frac{-e^{\alpha p_{i j}+\left(a, v_{i}\right)}}{\alpha\left(p_{i j}-c_{i j}\right)+1}, \quad i \in N_{j} .
$$

The right-hand side of this equation is the function $g(x)=$ $-e^{\alpha x+b} /\left(\alpha\left(x-c_{i j}\right)+1\right)$, where $b$ is a constant. The derivative of this function is

$$
g^{\prime}(x)=\frac{-\alpha^{2} e^{\alpha x+b}\left(x-c_{i j}\right)}{\left(\alpha\left(x-c_{i j}\right)+1\right)^{2}} .
$$

Consequently, $g(x)$ is a decreasing function for $x>c_{i j}$.

So the right side of the optimality equation (18) is a decreasing function in the equilibrium price $p_{i j}$ of player $i$. At the left side of the equation we have an expression, which depends on the prices of other players. If we introduce a new player to the link $e_{j}$, then the left side of the equation increases. Therefore, the root of the right side of the equation decreases. It can be proven by induction. We demonstrate it for the case $\left|N_{j}\right|=1$.

Let $\left|N_{j}\right|=1$. The equilibrium $p_{1 j}^{*}$ satisfies the equation

$$
e^{\rho}=\frac{-e^{\alpha p_{1 j}^{*}+\left(a, v_{1}\right)}}{\alpha\left(p_{1 j}^{*}-c_{1 j}\right)+1} .
$$

In the game with additional player the equilibrium price $\tilde{p}_{1 j}^{*}$ of the first player satisfies the equation

$$
e^{\rho}+e^{\alpha \widetilde{p}_{2 j}^{*}+\left(a, v_{2}\right)}=\frac{-e^{\alpha \widetilde{p}_{1 j}^{*}+\left(a, v_{1}\right)}}{\alpha\left(\widetilde{p}_{1 j}^{*}-c_{1 j}\right)+1} .
$$

Monotonicity of the function $g(x)$ gives $p_{1 j}^{*}>\widetilde{p}_{1 j}^{*}$.
Corollary 2. In the price game with additional player the optimal payoffs of all players except the new one are decreasing; that is, $\forall i \in N_{j}$ holds. Consider

$$
h_{i j}\left(\left\{p_{i j}^{*}\right\}_{i \in N_{j}}\right)>h_{i j}\left(\left\{\tilde{p}_{i j}^{*}\right\}_{i \in \widetilde{N}_{j}}\right) .
$$

Proof. In the equilibrium (18) holds for player $i$. Substituting it in to the payoff of player $i$ gives

$$
\begin{aligned}
h_{i j} & \left(\left\{p_{i j}^{*}\right\}_{i \in N_{j}}\right) \\
& =\left(p_{i j}^{*}-c_{i j}\right) \frac{e^{\alpha p_{i j}^{*}+\left(a, v_{i}\right)}}{e^{\rho}+\sum_{r \in N_{j} \backslash\{i\}} e^{\alpha p_{r j}^{*}+\left(a, v_{r}\right)}+e^{\alpha p_{i j}^{*}+\left(a, v_{i}\right)}} d\left(e_{j}\right) .
\end{aligned}
$$

Hence, we obtain

$$
h_{i j}\left(\left\{p_{i j}^{*}\right\}_{i \in N_{j}}\right)=\left(p_{i j}^{*}-c_{i j}+\frac{1}{\alpha}\right) d\left(e_{j}\right) .
$$

According to the theorem the equilibrium prices in the game with additional player are decreasing. Consequently, the optimal payoffs in (24) also decrease if a new service is introduced on the link $e_{j}$.

Let us return to location game. On the first stage the players distribute their resources among links. After resource allocation price game takes place on each link and the players receive some payoffs. We obtain in the theorem that these payoffs are decreasing functions in the number of players choosing the same link.

The game of this type is a so-called congestion game. In paper [10] it was proven that equilibrium in pure strategies exists in these games. Equilibrium point can be found as a result of best response process.

\section{Location-Price Competition in Airline Networks}

Let $V$ be a finite set of airports and let $E$ be a finite set of routes between airports. Under route we mean that any airline can perform operations between these two airports. An undirected graph $G(V, E)$ represents possible routes between airports in airline market.

An airline is considered as a player in the market. Each airline $i$ allocates $m_{i}$ planes among routes in $G(V, E)$. We make a restriction that airline cannot allocate more than one plane to a single route. Note that one plane can serve many airline routes, if it performs a flight with several connections.

Let us define $x_{i}$ as an airline allocation vector and $E^{i}$ as an airline route network.

Each route $e_{j}$ in $G(V, E)$ is characterized by potential passenger demand $d\left(e_{j}\right)$. Airline share in route passenger demand $M_{i j}$ depends on airline own price $p_{i j}$ and prices of competitive airlines. For simplicity, we assume that airline operating costs on the route $e_{j}$ are proportional to passenger demand. 
TABLE 1: Summary statistics (Russian market).

\begin{tabular}{|c|c|c|c|c|c|}
\hline Factor & Mean & Standard deviation & Median & Min & Max \\
\hline Price (rub.) & 9831 & 4111 & 9425 & 1500 & 21630 \\
\hline Flight time (h.) & 3.34 & 2.33 & 2.4 & 0.4 & 15.3 \\
\hline Frequency (flights per week) & 2.8 & 2.04 & 1 & 1 & 14 \\
\hline Distance $(\mathrm{km})$ & 1774 & 1263 & 1486 & 215 & 7314 \\
\hline Income (rub./year) & 27053 & 10390 & 22224 & 14167 & 50991 \\
\hline Population & 499430 & 394948 & 327423 & 44334 & 1498921 \\
\hline
\end{tabular}

TABLE 2: Summary statistics (Chinese market).

\begin{tabular}{|c|c|c|c|c|c|}
\hline Factor & Mean & Standard deviation & Median & Min & Max \\
\hline Price (rmb.) & 1366 & 537 & 1300 & 540 & 2910 \\
\hline Flight time (h.) & 2.23 & 1 & 2.08 & 0.75 & 5.72 \\
\hline Frequency (flights per week) & 6.4 & 1.44 & 7 & 1 & 7 \\
\hline Distance $(\mathrm{km})$ & 1298 & 657 & 1233 & 351 & 3388 \\
\hline Income (rmb./year) & 29501 & 6903 & 28731 & 18400 & 40742 \\
\hline Population (ths.) & 10968.7 & 7347.4 & 9325.05 & 2141.3 & 29190 \\
\hline
\end{tabular}

Hence, the gain, which an airline gets from operating on the route $e_{j} \in E^{i}$, can be written down as (7) and total airline payoff in the market equals (8).

To describe airline competitive behavior, we will consider the following game, where prices and allocation vectors are set as airlines strategies.

(1) Airlines simultaneously select planes allocation $\left\{x_{i}\right\}_{i \in N}$ among routes.

(2) Airlines simultaneously select prices in their networks $\left\{p_{i}\right\}_{i \in N}$

(3) As a result of these decisions, passengers select flights and airlines receive payoffs $\left\{H_{i}\right\}_{i \in N^{*}}$.

We study Nash equilibrium for allocation vectors $\left\{x_{i}\right\}_{i \in N}$, knowing that in the second stage of the game players choose prices $\left\{p_{i}\right\}_{i \in N}$ from Nash equilibrium for fixed airline networks on graph $G(V, E)$.

4.1. Passenger Demand. In order to proceed with analyzing equilibrium prices and locations we need to specify how passenger demand is distributed between competitive airlines. We consider here that potential demand for the route $e_{j}$ depends on the population size in airport regions and equals

$$
d\left(e_{j}\right)=\frac{\sqrt{P\left(v_{j}^{1}\right) P\left(v_{j}^{2}\right)}}{2}, \quad e_{j}=\left(v_{j}^{1}, v_{j}^{2}\right)
$$

where $P$ defines population size in airport region.

Multinomial logit model is used to compute airline shares in passenger demand. We assume that a passenger considers price and airline route characteristics to choose between competitive airlines. Airline route characteristics are combined in vector $k_{i j}$. Hence, airline share in passenger demand on the route $e_{j}$ equals

$$
M_{i j}\left(p_{i j},\left\{p_{r j}\right\}_{r \in N_{j} \backslash\{i\}}\right)=\frac{e^{a_{1} p_{i j}+\left(a, k_{i j}\right)}}{\sum_{s=1}^{\left|N_{j}\right|} e^{a_{1} p_{s j}+\left(a, k_{s j}\right)}+e^{\rho}}, \quad e_{j} \in E^{i},
$$

where $a_{1}<0$ and $a$ is a vector of constants. We include the additional term in denominator to capture passenger alternative not to travel by plane.

4.2. Examples of Airline Markets. We illustrate presented model with an application to Russian and Chinese airline markets (Figures 1 and 2). Market statistics are shown in Tables 1 and 2 .

The Russian market contains 27 airports with 95 routes in $G(V, E)$. There are 239 single-trip flights and 74 flights with connections. The number of airlines is 11 and the maximum number of competitive airlines on a single route equals 5. The Chinese market has 14 airports with 61 routes in $G(V, E)$. There are 351 single-trip flights and 14 flights with connections. The number of airlines is 5 and the maximum number of competitive airlines on a single route equals 3 .

Airline route characteristics in Russian case include flight time, dummy variable $\gamma_{i j}$ to indicate direct flight, geometric mean of income rates in airport city pair, and distance between airports:

$$
\tilde{k}_{i j}=a_{2} t_{i j}+a_{3} \gamma_{i j}+a_{4} \text { income }_{i j}+a_{5} \ln \left(\text { dist }_{i j}\right), \quad e_{j} \in E^{i} .
$$

Airline share is expected to drop on price and flight time increase. On the distance growth planes become more competitive between other means of transport and airline share should increase.

We include the same route characteristics for the Chinese market and also add airline loading indicator, which equals 


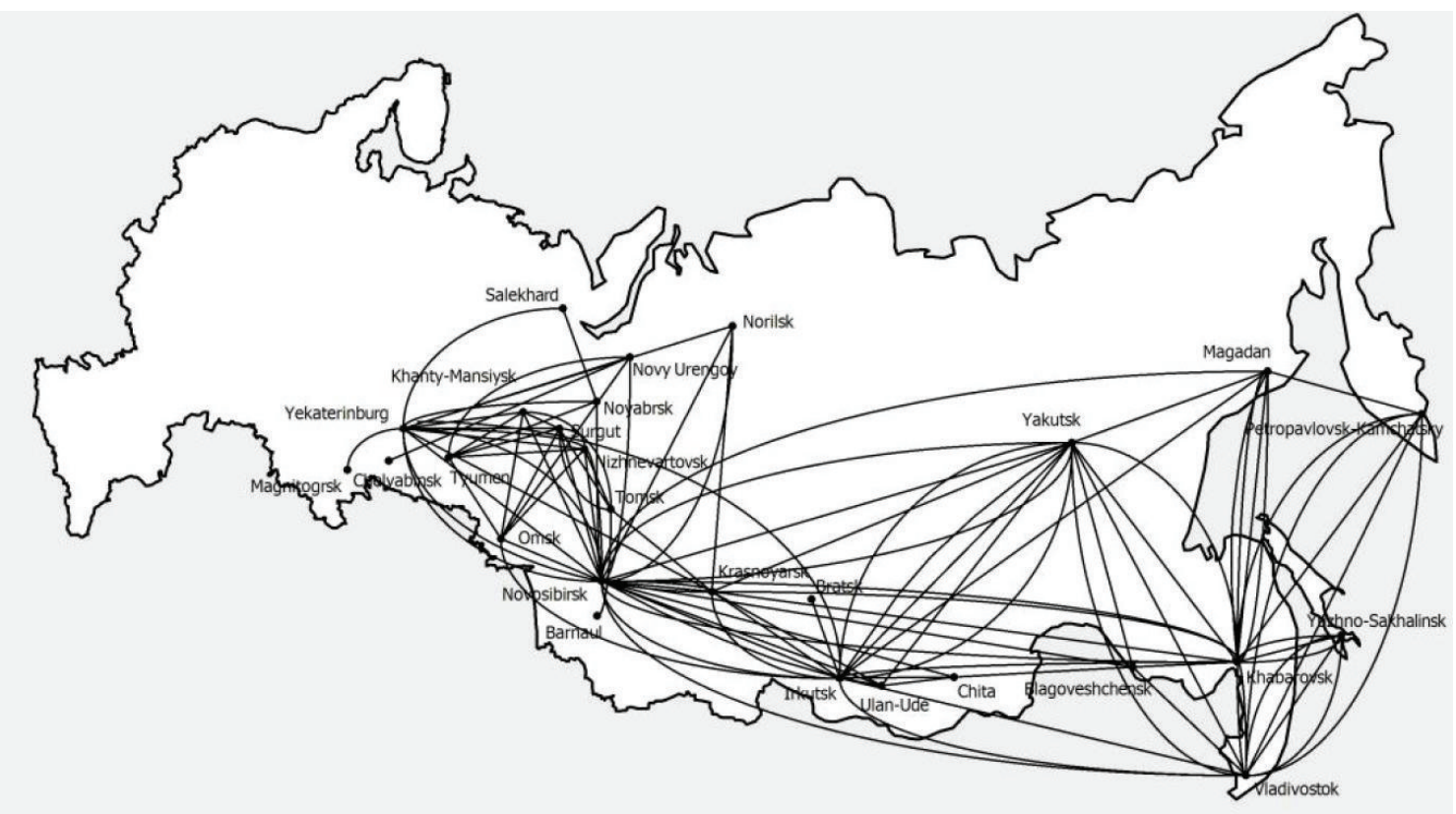

FIGURE 1: Russian airline market.

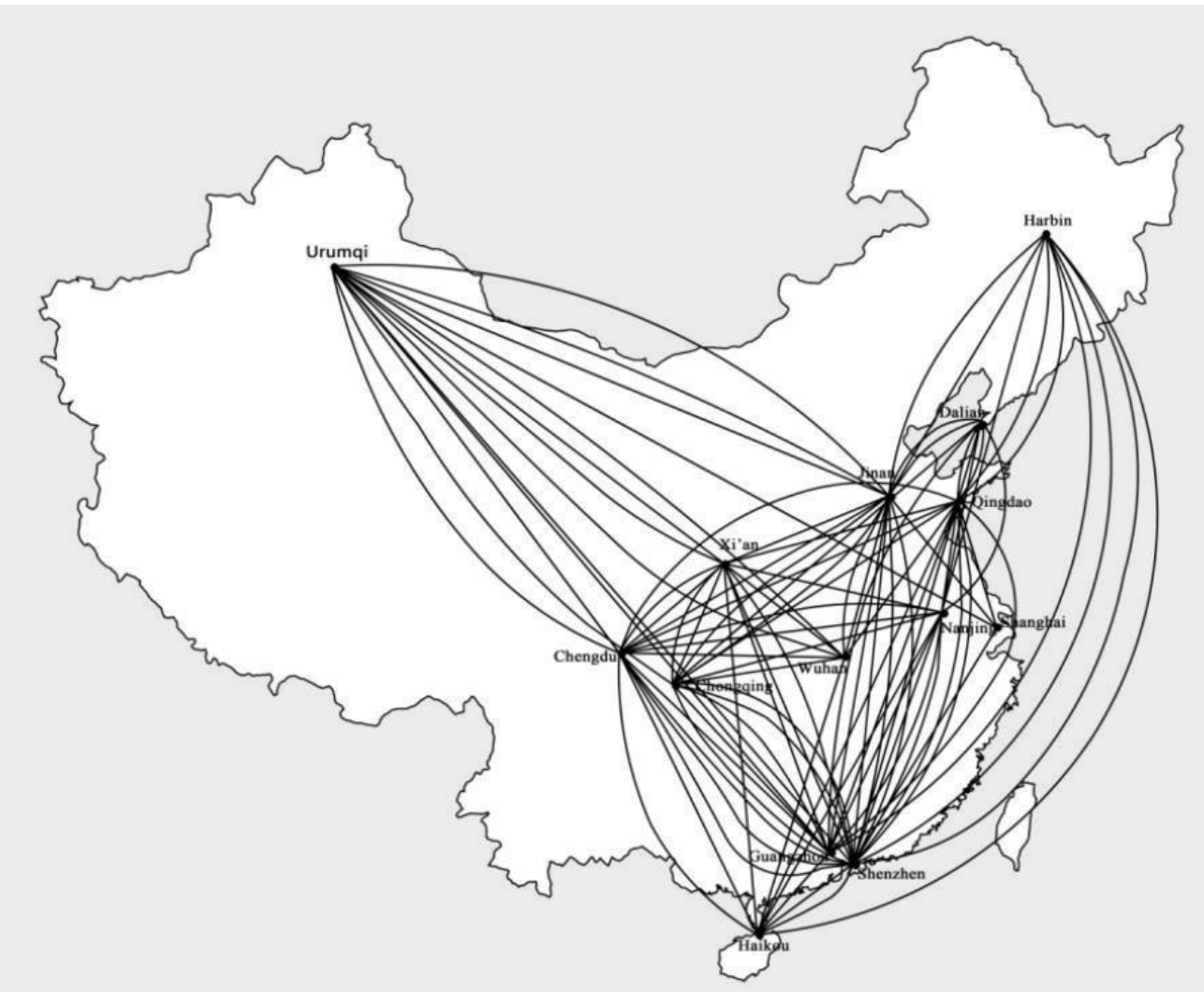

FIgURE 2: Chinese airline market. 
TABle 3: Parameter estimation results.

\begin{tabular}{cccccccc}
\hline & $a_{1}$ & $a_{2}$ & $a_{3}$ & $a_{4}$ & $a_{5}$ & $a_{6}$ & Constant \\
\hline Russia & -0.000656 & -0.288 & 0.628 & 0.000141 & 3.83 & -28.305 \\
China & -0.00196 & -1.138 & 0.135 & 3.845 & -6.571 & 1.142 & 3.845 \\
\hline
\end{tabular}

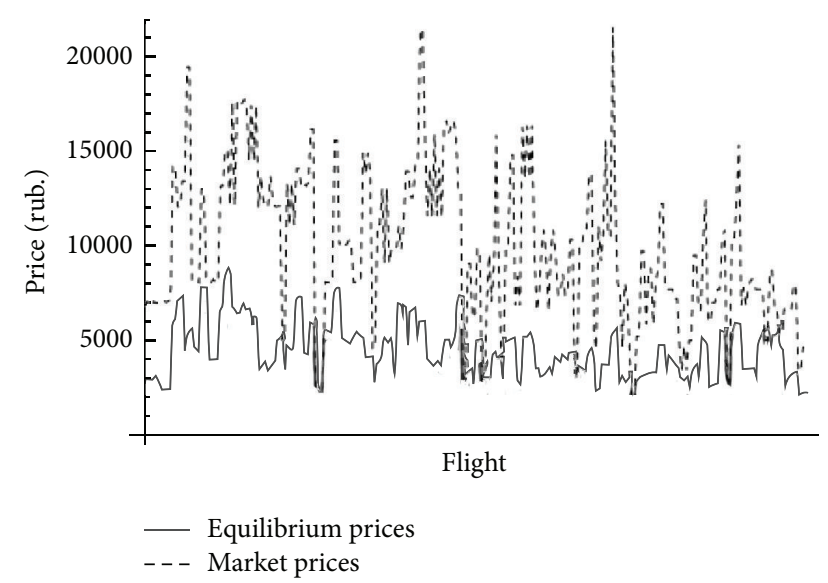

FIGURE 3: Equilibrium prices (Russian market).

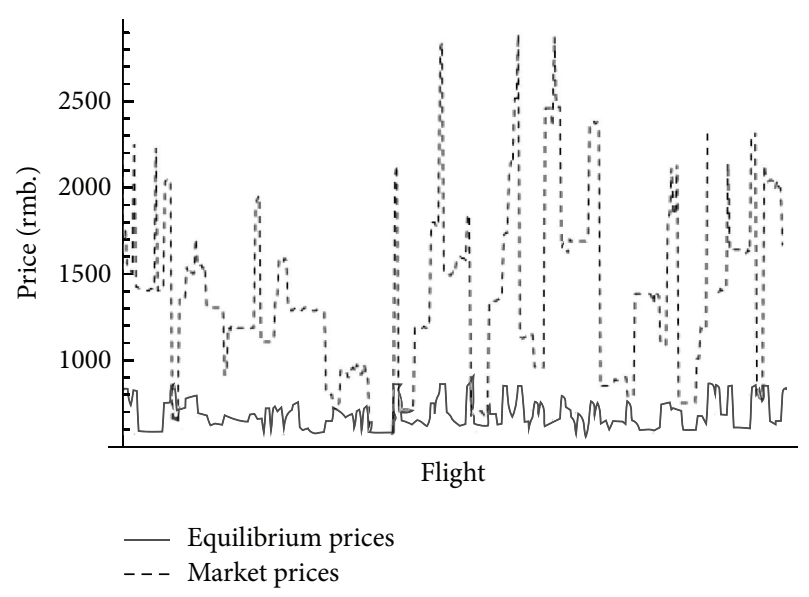

FIGURE 4: Equilibrium prices (Chinese market).

1 if average seat occupancy is more than $80 \%$. Time, income, and distance values represent these factor values divided by the minimum value of the same factor in the considered route. Hence,

$$
\begin{aligned}
\widetilde{k}_{i j}= & a_{2} t_{i j}^{\text {ratio }}+a_{3} \gamma_{i j}+a_{4} \text { income }_{i j}^{\text {ratio }} \\
& +a_{5} \text { dist }_{i j}^{\text {ratio }}+a_{6} \text { loading }_{i j}, \quad e_{j} \in E^{i} .
\end{aligned}
$$

We performed parameter estimation in (26) using BLP method [11] with flight fuel consumption taken as instrumental variable. Estimation results are presented in Table 3.

4.3. Price Competition. Location-price competition in airline market is examined using backward induction. First, we analyze price game, when airlines have already specified

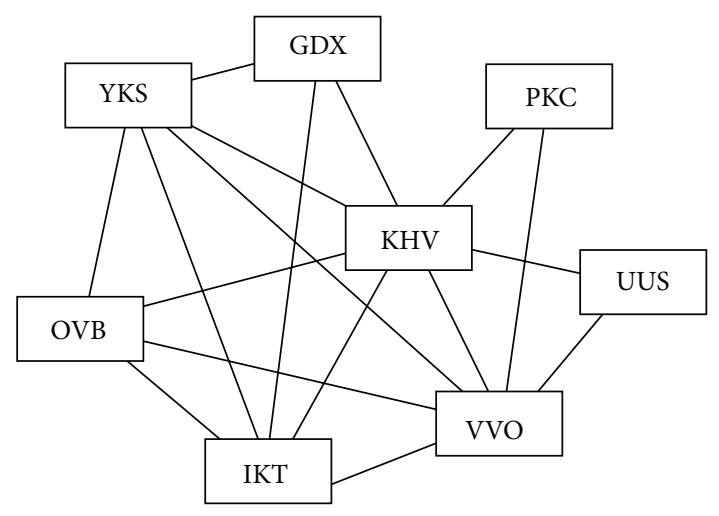

Figure 5: Market graph (Russia).

planes allocation among routes in $G(V, E)$. After that, Nash equilibrium in location game is considered.

Airline share in route passenger demand depends on its own price and the prices of other airlines, which compete on this route. The existence and uniqueness of equilibrium for prices on the route $e_{j}$ follows from [9].

In Nash equilibrium airline price is a best response to the equilibrium prices of other airlines on the considered route $e_{j}$. The first-order condition for airline best response is given in the following equation:

$$
\left(1-M_{i j}\right)\left(c_{i j}-p_{i j}\right)=\frac{1}{a_{1}}
$$

In Figures 3 and 4 prices in equilibrium, which were computed from (29) for each route, are compared with real market prices used by airlines. Flights are ordered by airport city pairs. Note that only fuel consumption is included in airline costs, which leads to smaller price values in equilibrium.

4.4. Location Game. Let us return to the first stage of the game, when airlines select operating routes in $G(V, E)$. We picked out a subgraph in both considered markets for two competitive airlines (Figures 5 and 6). Airline A has 11 (7) planes with 158 (164) seats and airline B has 9 (6) planes with 150 (164) seats in these two examples. Operating networks are presented in Figure 7 for the Russian market and in Figure 8 for the Chinese market.

We derive allocation vectors in equilibrium with the following procedure. First, airline A optimally allocates all planes among routes. Airline B planes enter a market consequentially. Each time we find location equilibrium in the market for all planes of airline A and present planes of airline $\mathrm{B}$ using best response dynamics. One can show that the best response sequence converges to an equilibrium using the fact that airline payoff in equilibrium decreases, when a new airline enters the market on the route $e_{j}$. 


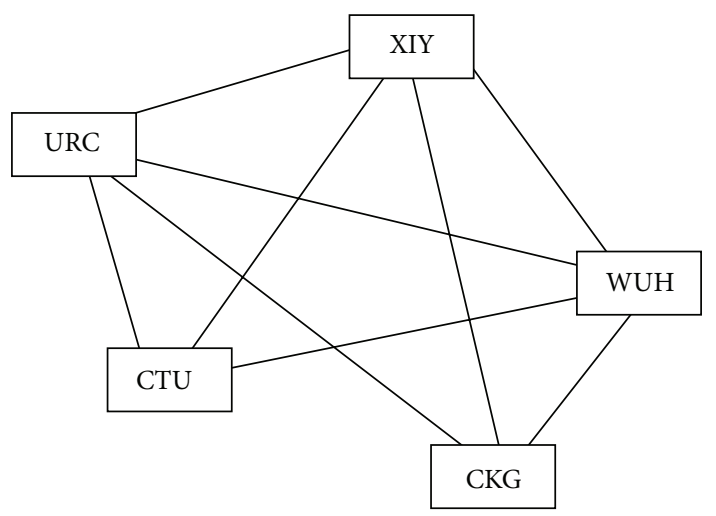

Figure 6: Market graph (China).

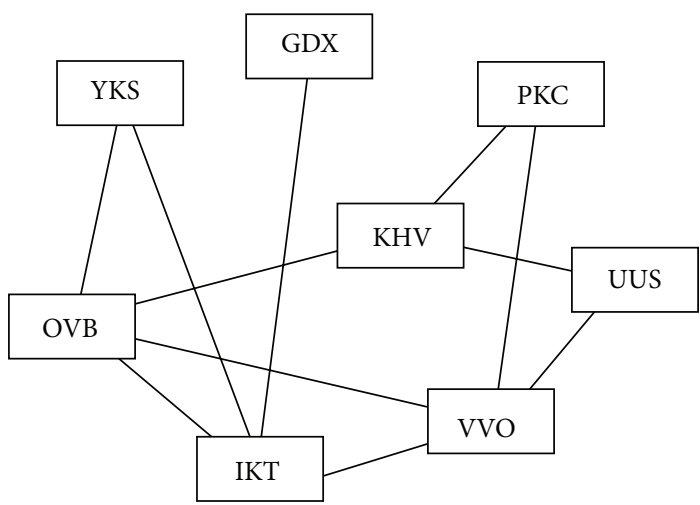

(a) Network A

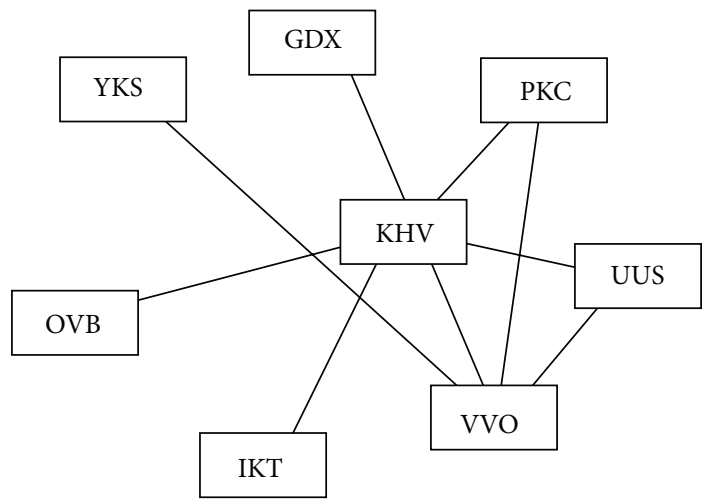

(b) Network B

FIgURE 7: Operating networks (Russia).

Equilibrium airline networks are shown in Figures 9 and 10. Note that in the real market airline B behaves the same as in the model location equilibrium in the Russian case and switches 2 planes in the Chinese case. Airline A switches 2 planes to new routes in the equilibrium in both examples.

\section{Conclusion}

This paper studies location-then-price game as a two-stage game of $n$ players on the graph. Logit analysis is used to model demand distribution between competitors. The use of

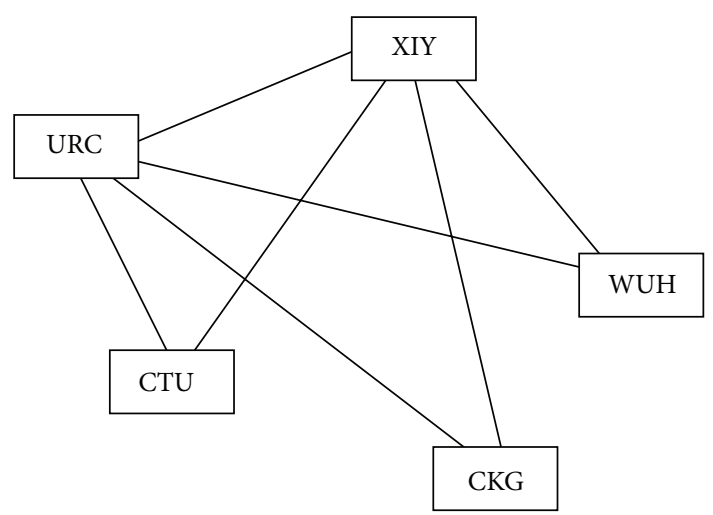

(a) Network A

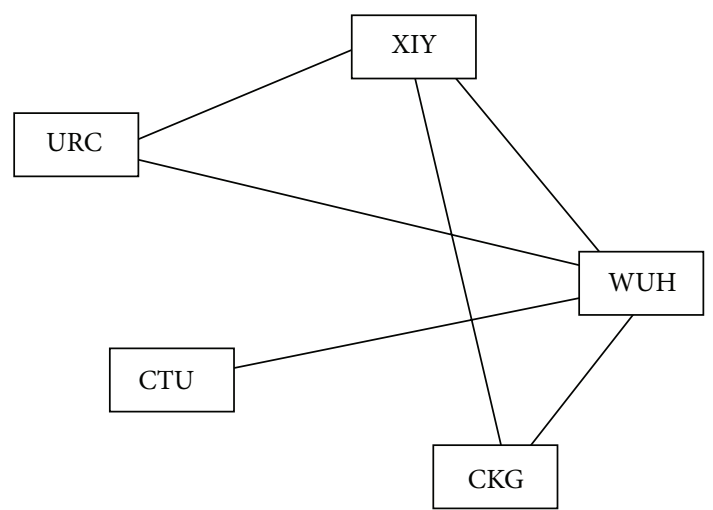

(b) Network B

FIGURE 8: Operating networks (China).

multinomial logit model allows us to compute shares in case of $n$ players and proceed with studying price equilibrium. Price and location equilibria are constructed using best response dynamics. We apply proposed model to Russian and Chinese airline markets and find location and price equilibria for competitive airlines.

Our research can be extended in several directions. Airline competitiveness is also affected by the choice of base airports and hubs in operating network. Our model does not address these issues. Multinomial logit model belongs to a class of discrete choice models and development of location-then-price game for other models in discrete choice analysis can extend model applicability. Routes scheduling, airline mergers, and other airline market specific features are not considered. Complex analysis of competitive behavior in airline market is an open problem for further research.

\section{Appendix}

The list of IATA codes that are used in the text are presented in Tables 4 and 5.

\section{Conflict of Interests}

The authors declare that there is no conflict of interests regarding the publication of this paper. 


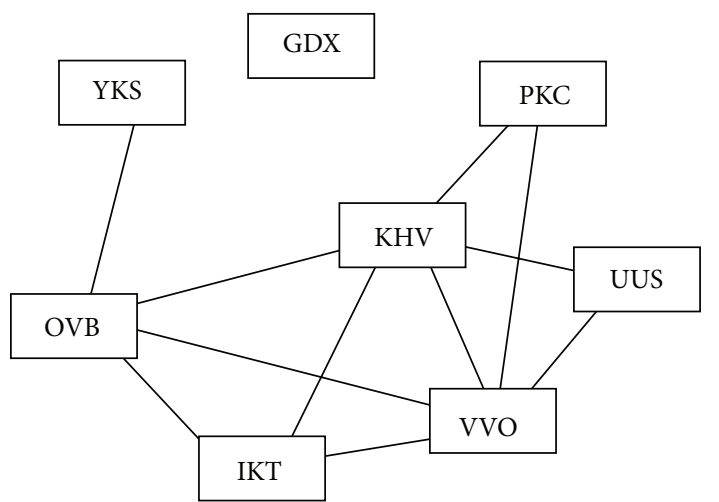

(a) Airline A allocation

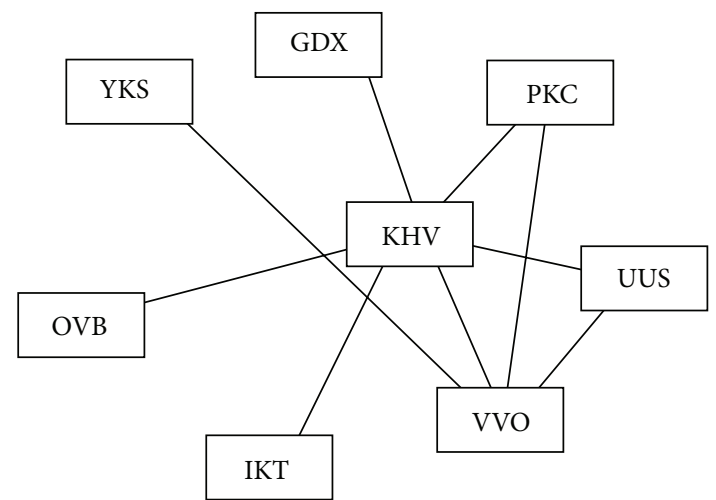

(b) Airline B allocation

FIGURE 9: Equilibrium in location game (Russia).

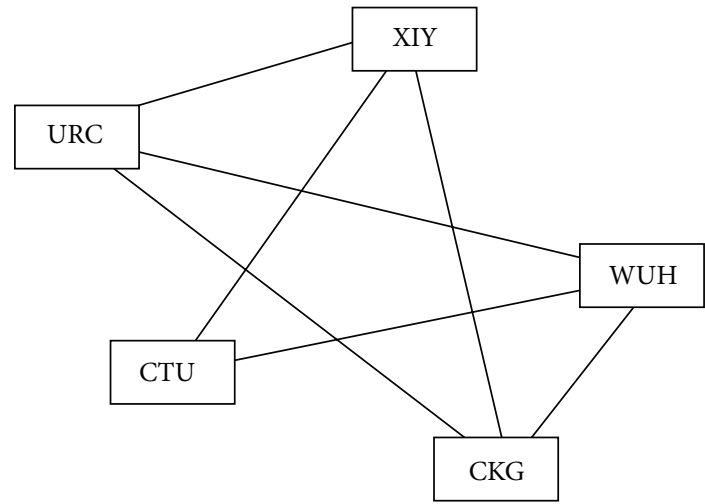

(a) Airline A allocation

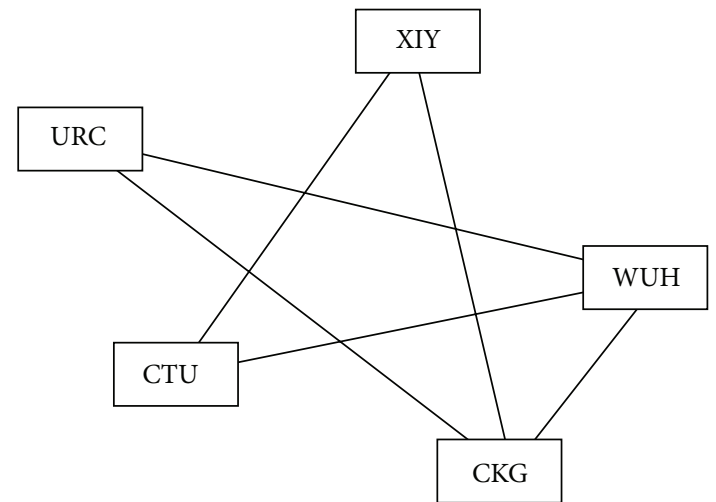

(b) Airline B allocation

FIgURE 10: Equilibrium in location game (China).

TABLE 4: Russian airports.

\begin{tabular}{lc}
\hline IATA & City \\
\hline GDX & Magadan \\
IKT & Irkutsk \\
KHV & Khabarovsk \\
OVB & Novosibirsk \\
PKC & Petropavlovsk-Kamchatsky \\
UUS & Yuzhno-Sakhalinsk \\
VVO & Vladivostok \\
YKS & Yakutsk \\
\hline
\end{tabular}

\section{Acknowledgments}

The research was supported by the Grant of the Russian Fund for Basic Research (Project no. 13-01-91158) and the Division of Mathematical Sciences of the Russian Academy of Sciences.
TABLE 5: Chinese airports.

\begin{tabular}{lc}
\hline IATA & City \\
\hline CKG & Chongqing \\
CTU & Chengdu \\
URC & Urumqi \\
WUH & Wuhan \\
XIY & Xian \\
\hline
\end{tabular}

\section{References}

[1] H. Hotelling, "Stability in competition," The Economic Journal, vol. 39 , no. 153 , pp. $41-57,1929$.

[2] C. d'Aspremont, J. Gabszewicz, and J.-F. Thisse, "On Hotelling's "stability in competition"', Econometrica, vol. 47, no. 5, pp. 11451150, 1979.

[3] N. Economides, "Minimal and maximal product differentiation in Hotelling's duopoly," Economics Letters, vol. 21, no. 1, pp. 67$71,1986$. 
[4] S. Salop, "Monopolistic competition with outside goods," Bell Journal of Economics, vol. 10, no. 1, pp. 141-156, 1979.

[5] H. Ahn, S. W. Cheng, O. Cheong, and R. van Oostrum, "Competitive facility location: the Voronoi game," Theoretical Computer Science, vol. 310, no. 1-3, pp. 457-467, 2004.

[6] V. V. Mazalov and M. Sakaguchi, "Location game on the plane," International Game Theory Review, vol. 5, no. 1, pp. 13-25, 2003.

[7] V. V. Mazalov, A. V. Shchiptsova, and J. S. Tokareva, "Hotelling's duopoly and location game on the plane," Economy and Mathematical Methods, vol. 46, no. 4, pp. 91-100, 2010 (Russian).

[8] A. V. Mazalova, "Hotelling's duopoly in the Manhattan metric," Herald of the Saint Petersburg University, vol.10, no. 2, pp. 33-43, 2012 (Russian).

[9] A. Caplin and B. Nalebuff, "Aggregation and imperfect competition: on the existence of equilibrium," Econometrica, vol. 59, no. 1, pp. 25-59, 1991.

[10] I. Milchtaich, "Congestion games with player-specific payoff functions," Games and Economic Behavior, vol. 13, no. 1, pp. 111124, 1996.

[11] S. Berry, "Estimating discrete-choice models of product differentiation," The RAND Journal of Economics, vol. 25, no. 2, pp. 242-262, 1994. 


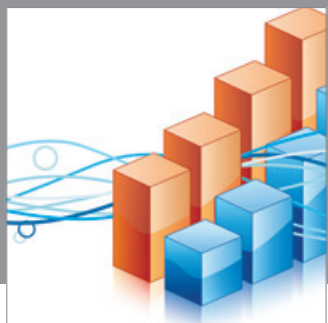

Advances in

Operations Research

mansans

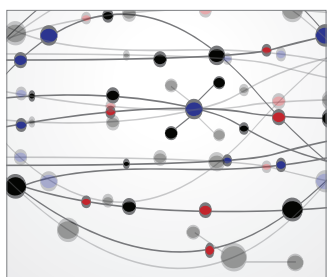

The Scientific World Journal
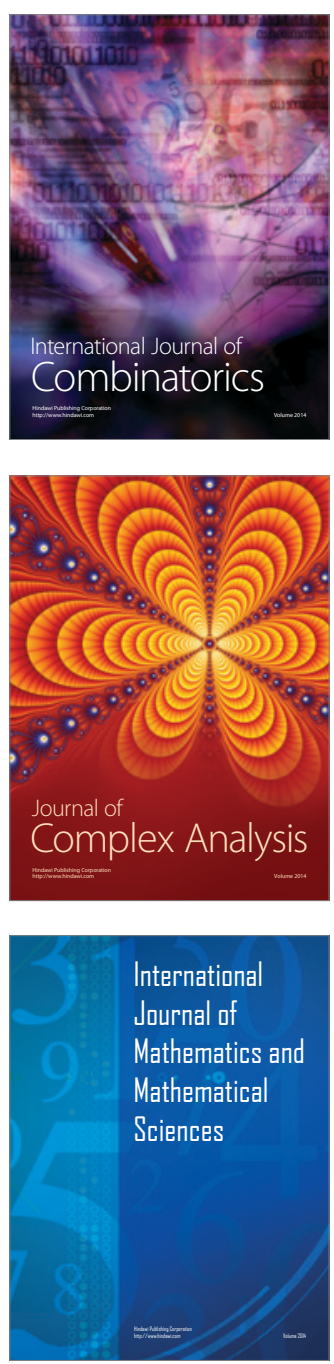
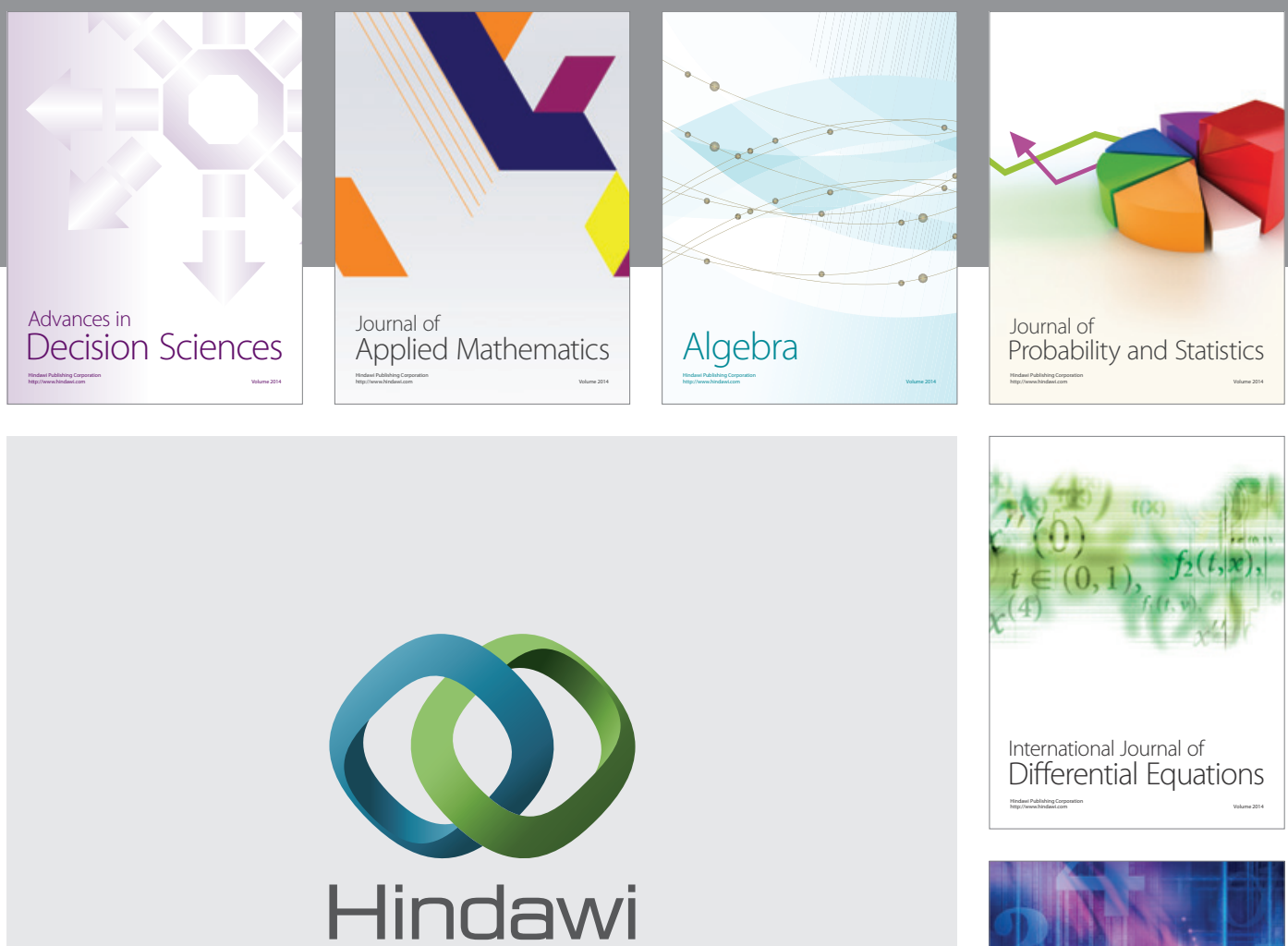

Submit your manuscripts at http://www.hindawi.com
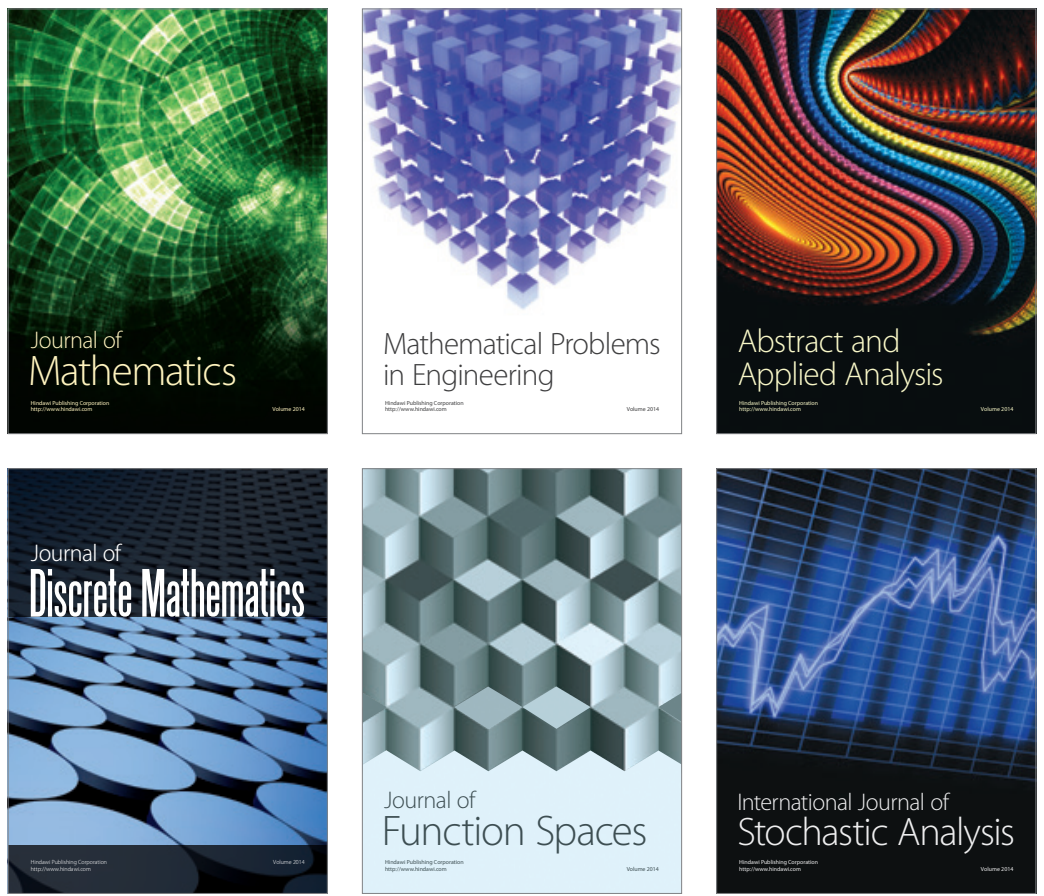

Journal of

Function Spaces

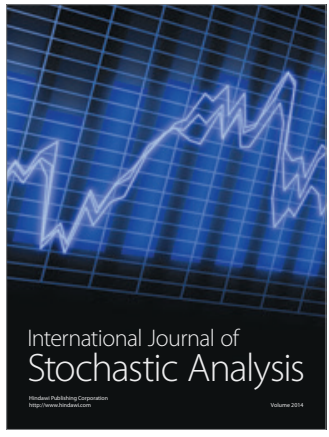

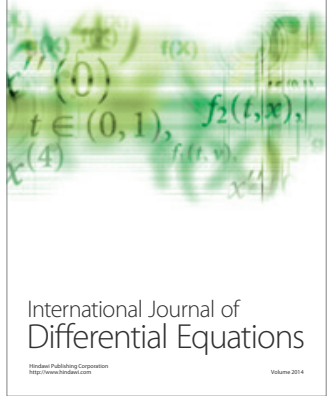
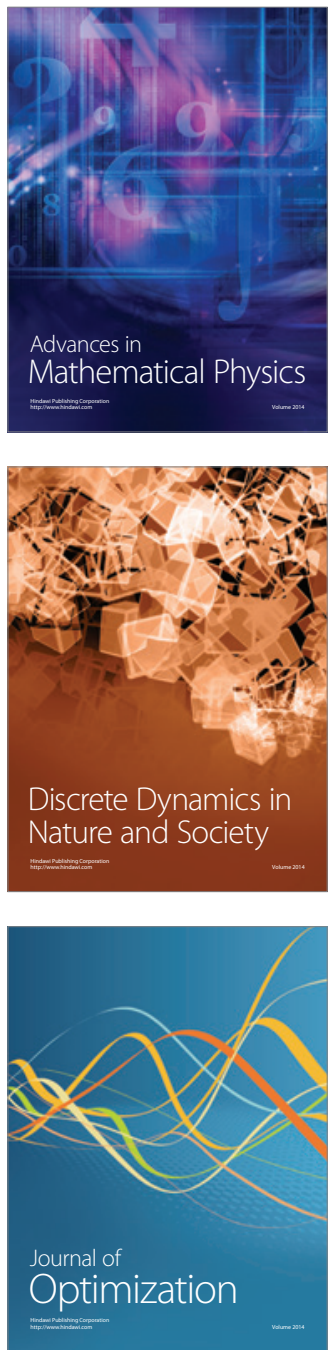